\title{
Evaluation of patients with
} abnormalities on intraoperative cholangiogram: time to abandon endoscopic retrograde cholangiopancreatography as the initial follow-up study

\author{
Jason G Bill, Vladimir M Kushnir, Daniel K Mullady, Faris M Murad, \\ Riad R Azar, Jeffery J Easler, Dayna S Early, Steven A Edmundowicz
}

Division of Gastroenterology, Washington University School of Medicine, St Louis, Missouri, USA

\section{Correspondence to} Dr Jason G Bill, Division of Gastroenterology, Washington University School of Medicine, 660 South Euclid Ave, Campus Box 8124, St Louis, MO 63110, USA; jbill@dom.wustl.edu

Presented in preliminary form at the Annual Digestive Diseases Week, 2014, Chicago, Illinois, USA.

Received 15 March 2015 Revised 28 May 2015 Accepted 30 May 2015 Published Online First 16 June 2015

\section{CrossMark}

To cite: Bill JG, Kushnir VM, Mullady DK, et al. Frontline Gastroenterology 2016:7:105-109.

\section{ABSTRACT}

Background Endoscopic retrograde

cholangiopancreatography (ERCP) is currently the method of choice for the postoperative

evaluation of suspected bile duct stones seen on intraoperative cholangiogram (IOC); however, the sensitivity of IOC for identifying biliary pathology is unclear, with studies reporting false positive rates between $30 \%$ and $60 \%$.

Objective Evaluate the sensitivity of IOC for biliary pathology, using ERCP with sphincterotomy and balloon sweep as gold standard.

Design Retrospective cohort study.

Patients 130 consecutive patients (age 51.3 \pm 1.7 years, $69.2 \%$ women) who underwent ERCP for the evaluation of abnormalities identified on IOC between 2005 and 2013.

Interventions Endoscopic retrograde cholangiopancreatography

Main outcome measurements Sensitivity of IOC, identify predictors of positive postoperative ERCP and ERCP-related complications.

Results ERCP was successful in all 130 subjects. ERCP-related adverse events occurred in six (4.3\%) patients, including self-limited postsphincterotomy bleeding in three $(2.3 \%)$ and mild post-ERCP pancreatitis in three (2.3\%). Overall, $41(31.5 \%)$ patients had normal cholangiogram at time of ERCP. Finding of a filling defect on IOC was the only predictor for the presence of common bile duct stones on postoperative ERCP (OR 3.3, 95\% Cl 1.0 to $10.8, p=0.05$ ).

Limitations Retrospective study design.
Conclusions Nearly one-third of patients with abnormal IOC had a normal postoperative ERCP. Significant pathology could have been missed in $1 / 130$ patients. Based on these findings, we believe the use of less-invasive diagnostic modalities may be used in place of ERCP in patients with suspected choledocholithiasis on IOC.

\section{BACKGROUND}

Cholelithiasis is one of the most prevalent digestive disorders in the USA, and one of the most common indications for abdominal surgery. ${ }^{1}$ Laparoscopic cholecystectomy (LC) is currently the standard therapy for symptomatic cholelithiasis. Intraoperative cholangiograms are widely used to demonstrate ductal morphology and to detect common bile duct stones (CBDS) during LC. ${ }^{2-5}$ While the performance of routine versus selective intraoperative cholangiogram (IOC) during LC remains controversial, a recent survey of the US Nationwide Inpatient Sample indicates that IOCs are performed in 33\% cases. ${ }^{6}$

Retained CBDS identified on IOC are typically extracted postoperatively by endoscopic retrograde cholangiopancreatography (ERCP) or interoperatively by laparoscopic CBD exploration. ${ }^{1}$ Due to the limited availability of laparoscopic CBD exploration, the vast majority of patients with abnormalities on IOC undergo a postoperative ERCP to clear 
the bile duct of stones. ${ }^{5}$ While ERCP is considered to be a safe and effective method of treating CBDS, ERCP is an invasive procedure, associated with a complication rate of up to $11 \%$ even in experienced hands. $^{7}$ Moreover, recent studies have indicated that IOC may carry a false positive rate of $30-67 \%$; thus, the question of whether ERCP is the most appropriate next step for patients with abnormalities on IOC has been raised. ${ }^{5} 8$

The aim of this study was to evaluate the false positive rate of IOC for CBDS using postoperative ERCP with biliary sphincterotomy and balloon sweep as the gold standard. Additionally, we wished to identify those patients with abnormal IOC who are most likely to harbour CBDS and thus most likely to benefit from postoperative ERCP.

\section{METHODS}

Consecutive adult patients ( $>18$ years old) undergoing ERCP for the evaluation of abnormalities on IOC at a single tertiary centre between July 2005 and August 2013 were retrospectively identified from the institutional endoscopic database (Provation MD, Minneapolis, Minnesota, USA). A manual chart review was performed and the pre-endoscopy history was extracted from each patient's electronic medical record; demographics (age, gender, weight, height) and clinical data (indication for LC, date of LC, findings on IOC, location where LC was performed, pre-ERCP liver function test results). Liver functions tests (LFTs) were considered abnormal if there was any elevation above the upper limit of the normal reference range in the transaminases, alkaline phosphatase or bilirubin. IOC findings were divided into two categories: (1) filling defect(s) suggestive of CBDS and (2) non-passage of contrast into the duodenum, without an obvious filling defect in the CBD.

ERCPs were performed at a hospital endoscopy unit by one of five experienced endoscopists or by an advanced endoscopy fellow under the direct supervision of the attending endoscopist. For the procedures, patients were under conscious sedation administered by the endoscopists or deep sedation administered by a nurse anaesthetist under the supervision of an attending anaesthesiologist. The ERCPs were performed with a standard duodenoscope (Olympus TJF 140-160). Successful ERCP was defined as deep cannulation of the bile duct followed by performance of the planned intervention. Use of pancreatic duct stents and pre-cut sphincterotomy was at the discretion of the attending endoscopist. During the study period, it was our group's practice to perform a biliary sphincterotomy and balloon sweep in all patients undergoing ERCP for suspected choledocholithiasis. IOC was considered false positive if pathology (stone, biliary sludge, stricture, bile leak) was not identified on postoperative ERCP. The ERCP findings, therapeutic interventions and complications were recorded.

\section{Statistical analysis}

Data are reported as mean \pm SD for normally distributed data, and median and range for skewed data. Grouped continuous variable data were compared using two-tailed Student's t test and Mann-Whitney $\mathrm{U}$ test where appropriate. Intergroup and categorical comparisons were made using the $\chi^{2}$ and Fisher's exact tests. A $p$ value of $<0.05$ was required for statistical significance. All statistical analyses were performed using PASW V.19.1 (SPSS, Chicago, Illinois, USA).

\section{RESULTS}

In total, 130 patients (age $51.3+1.7$ years, 90 women, $69.2 \%)$ were included in this study. Indications for LC included acute cholecystitis in $47(36.2 \%)$, biliary colic in $62(47.7 \%)$ and biliary pancreatitis in $21(16.2 \%)$ patients. Ninety patients (69.2\%) underwent LC at our medical centre, and the remaining 40 patients were referred from other institutions. The procedure for performing IOCs was not standardised as LCs were performed at multiple hospitals. All IOCs were interpreted by the referring surgeons. Findings on IOC that prompted referral or performance of ERCP included filling defect(s) in the biliary tree (116 patients, 89.2\%) and non-passage of contrast into duodenum (14 patients, 10.8\%). Mean time from cholecystectomy to ERCP was $7 \pm 1.8$ days.

ERCP was ultimately successful in all 130 subjects $(100 \%)$; however, the biliary tree could not be accessed in five $(3.9 \%)$ patients during the initial procedure and a second ERCP was required at which time biliary access was obtained. Biliary cannulation was considered difficult in $8(6.2 \%)$ cases, pancreatic duct stent was placed in $14(10.8 \%)$ and pre-cut sphincterotomy was performed in $4(3.1 \%)$ cases. Overall, 41 patients $(31.5 \%)$ had normal cholangiograms at the time of ERCP, CBDS were seen in 87 (66.9\%), malignant biliary stricture in $1(0.8 \%)$ and bile leak in $1(0.8 \%)$. Thus, the findings on ERCP and IOC were discordant in $32.3 \%$ of cases. Post-ERCP adverse events occurred in six (4.3\%) patients, including self-limited post-sphincterotomy bleeding in three $(2.3 \%)$ and mild post-ERCP pancreatitis in three $(2.3 \%)$. The overall adverse event rate was $7.9 \%$ (failed initial ERCP and/or post-ERCP complication).

On univariate analysis, finding of a filling defect on IOC (vs other IOC findings) was the only significant predictor for the presence of CBDS on postoperative ERCP $(\mathrm{p}=0.029)$ (table 1).

Logistic regression analysis was performed to further evaluate factors associated with the presence of CBDS on postoperative ERCP; all variables with a $\mathrm{p}$ value $<0.50$ were included in the model (table 2 ). 
Table 1 Predictors of a normal postoperative cholangiogram

\begin{tabular}{|c|c|c|c|}
\hline Variables & $\begin{array}{l}\text { Normal postoperative } \\
\text { cholangiogram }(n=41)\end{array}$ & $\begin{array}{l}\text { Abnormal postoperative } \\
\text { cholangiogram }(n=89)\end{array}$ & $\mathrm{p}$ Value \\
\hline \multicolumn{4}{|l|}{ Demographics } \\
\hline Female gender & $75.6 \%(31)$ & $66.3 \%(59)$ & 0.29 \\
\hline Age $($ mean \pm SEM) & $49.8 \pm 2.8$ years & $52 \pm 2.2$ years & 0.31 \\
\hline Cholecystectomy at tertiary centre & $70.7 \%(29)$ & $68.5 \%(61)$ & 0.6 \\
\hline \multicolumn{4}{|l|}{ Indication for surgery } \\
\hline Acute cholecystitis & 18 & 35 & 0.08 \\
\hline Biliary colic & 12 & 42 & \\
\hline Biliary pancreatitis & 11 & 12 & \\
\hline \multicolumn{4}{|l|}{$10 C$ finings } \\
\hline Filling defect & $80.5 \%(33)$ & $93.3 \%(83)$ & 0.029 \\
\hline Non-passage of contrast & $19.5 \%(8)$ & $6.7 \%(6)$ & \\
\hline \multicolumn{4}{|l|}{ ERCP finding } \\
\hline Periampullary diverticulum & $7.3 \%(3)$ & $7.8 \%(7)$ & 0.91 \\
\hline Duct diameter (mean \pm SEM) & $8.5 \pm 0.3 \mathrm{~mm}$ & $8.7 \pm 04 \mathrm{~mm}$ & 0.7 \\
\hline Time to ERCP (mean \pm SEM) & $9.6 \pm 5.3$ days & $5.9 \pm 2.5$ days & 0.4 \\
\hline Abnormal liver enzymes & $65.9 \%(27)$ & $68.5 \%(61)$ & 0.76 \\
\hline
\end{tabular}

ERCP, endoscopic retrograde cholangiopancreatography; IOC, intraoperative cholangiogram.

In the model, finding of a filling defect on IOC was the only predictor for the presence of CBDS on postoperative ERCP (OR 3.3, 95\% CI 1.0 to 10.8, $\mathrm{p}=0.05)$.

\section{DISCUSSION}

In this retrospective study, we found $31.5 \%$ of patients referred for ERCP following a suspected bile duct stone being identified on IOC had a normal postoperative ERCP. The only factor associated with finding a stone on postoperative ERCP was an IOC finding of filling defect in the biliary tree. Moreover, ERCP in this setting resulted in short-term adverse outcomes in $8 \%$ of patients.

Despite almost 30 years of experience with LC, there remains debate about whether IOC should be used universally or be employed selectively in highrisk patients. ${ }^{9}$ This is in large part due to the fact that the predictive value of preoperative risk stratification algorithms has been disappointing; thus, some have continued to advocate for universal application of

Table 2 Multivariable analysis: predictors of a normal postoperative cholangiogram

\begin{tabular}{llll}
\hline & OR & $95 \% \mathrm{Cl}$ & $\mathrm{p}$ Value \\
\hline Age & 0.99 & 0.97 to 1.0 & 0.41 \\
Female gender & 1.6 & 0.66 to 3.9 & 0.30 \\
Time from LC to ERCP & 1.0 & 0.99 to 1.1 & 0.42 \\
Finding on IOC & \multicolumn{3}{l}{} \\
$\quad \begin{array}{lll}\text { Stricture/ non-passage of contrast } \\
\quad 1 \text { (reference) }\end{array}$ \\
$\quad 3.3$ & 1.0 to 10.8 & 0.05 \\
\hline $\begin{array}{l}\text { Filling defect } \\
\text { intraoperative cholangiogram; LC, laparoscopic cholecystectomy. }\end{array}$
\end{tabular}

IOC during LC performed for therapy of gallstone disease. $^{8-13}$ Not unexpectedly, this has led to a marked increase in the use of ERCP in the era of lap-

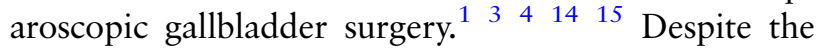
almost universal adoption of ERCP as a follow-up study to abnormalities identified on IOC, the optimal evaluation of patients with abnormal IOC findings is incompletely defined. Similar to the present study, Spinn $e t a l^{8}$ and Varadarajulu et $a l^{5}$ have found that a sizable minority of patients who undergo ERCP for follow-up of abnormalities on IOC have no biliary pathology identified on cholangiogram or balloon sweep. Indeed, in a recent review of randomised trials evaluating the use of IOC during LC, Ford et al found that while the sensitivity and negative predictive value of IOC for choledocholithiasis was excellent $(>96 \%)$, the positive predictive value of IOC was at best fair, at $56 \% .{ }^{16}$ Taken together, these data suggest that IOC is a good tool to screen patients for choledocholithiasis at the time of LC but should not be relied upon as a gold standard.

The reasons behind the poor positive predictive value of IOC in evaluating for choledocholithiasis are incompletely defined. First and foremost, the spontaneous passage of stones out of the CBD has been reported to occur in $21 \%$ of patients during intermediate term follow-up and likely an even higher proportion of those with very small stones or sludge in the biliary tree. ${ }^{17}$ Other factors such as periampullary diverticula, papillary stenosis or passage of air bubbles into the biliary tree may lead also to false positive findings on IOC. Finally, interpretation of IOC findings can be challenging with one study showing that biliary anatomy was interpreted correctly in $<25 \%$ of IOCs when a bile duct injury occurred. ${ }^{18}$ All this 
taken together with the non-trivial morbidity of ERCP leads us to argue that additional clinical or imaging assessment should be performed prior to performing ERCP for follow-up of abnormalities identified on IOC.

Two prior studies have attempted to identify clinical predictors of finding choledocholithiasis on postoperative ERCP, with conflicting results. In a prospective study, Varadarajulu et $a l^{5}$ found that LFT abnormalities immediately prior to ERCP were associated with finding stones on ERCP. However, a subsequent study by Spinn et $a l^{8}$ failed to identify any factors, including LFTs, as predictors of identifying choledocholithiasis at the time of ERCP. We did not observe an association between LFT abnormalities and finding of retained stone. This discrepancy may be partially explained by the fact that LFTs were not measured at a standardised time point prior to ERCP in the latter two cohorts; given the fact that liver chemistries can normalise rapidly following passage of a CBDS, this finding has to be interpreted with caution. ${ }^{8}$ In the present study, we did find that an IOC finding of a filling defect/stone on IOC was associated with choledocholithiasis at the time of ERCP. It should be noted that Varadarajulu et $a l^{5}$ also observed that finding large or multiple stones on IOC was associated with positive findings on postoperative ERCP. Given the inconsistent performance of clinical predictors in risk-stratifying patients with abnormal IOC to identify choledocholithiasis on postoperative ERCP, non-invasive imaging modalities such as endoscopic ultrasound (EUS) or MR cholangiopancreatography (MRCP) can be used to further evaluate patients with abnormalities on IOC, particularly as these less-invasive modalities have accuracy in excess of 95\% for identifying bile duct calculi. ${ }^{8} 19-21$ Thus, the use of these less-invasive modalities should be considered in order to minimise unnecessary ERCPs, particularly in the subset of patients with normal postoperative LFTs and equivocal findings on IOC. With this in mind, however, the limitations of EUS and MRCP have to be taken into consideration if one elects to pursue a less-invasive approach to following an abnormal IOC, as stones smaller than $5 \mathrm{~mm}$ in size and bile duct injury can be missed without direct cholangiography.

The major limitation of our study is its retrospective nature and limitations inherent to this study design. More specifically, our assessments of clinical risk factors for choledocholithiasis on postoperative ERCP were limited by the lack of central review of IOC images and inconsistent timing of postoperative LFT measurements. Furthermore, test performance characteristics for IOC could not be calculated as only patients with abnormal findings on IOC were referred for postoperative ERCP. However, our results are in line with the existing literature, and the rate of false positive IOCs is similar to that observed in prior prospective studies.
In summary, about one-third of patients with abnormal IOC had a normal postoperative ERCP. The finding of choledocholithiasis on postoperative ERCP was only associated with the finding of a filling defect on IOC (vs other IOC findings). Based on these findings, we believe the use of less-invasive diagnostic modalities (EUS or MRCP) may be used in place of ERCP in patients with suspected choledocholithiasis on IOC, particularly when a stone is not clearly visualised at the time of surgery.

\section{Significance of this study}

What is already known about this topic?

ERCP remains the method of choice for the postoperative evaluation of bile duct stones seen on intraoperative cholangiography.

\section{What this study adds?}

$31.5 \%$ of patients with abnormal IOC had normal postoperative ERCP. Significant pathology could have been missed in 1/130 patients.

How might it impact clinical practice in the foreseeable future?

Additional clinical or imaging assessment should be considered prior to performing ERCP for follow-up of abnormal intraoperative cholangiography.

Contributors JGB: primary author and responsible for data collection. VMK: primary investigator on this retrospective cohort study; responsible for data collection; was the primary editor for the corresponding author; and was a mentor to the primary author. DSE, DKM, RRA and FMM: responsible for editing abstract and manuscript, and formulated database. SAE: responsible for editing abstract and manuscript. JJE: responsible for editing manuscript and formulating database.

Competing interests None declared.

Ethics approval Institutional Review Board at Washington University School of Medicine/Barnes Jewish Hospital in St. Louis.

Provenance and peer review Not commissioned; externally peer reviewed.

Data sharing statement Data for this study are currently available to only the primary and corresponding authors. Data are currently stored on secure computers that authors can access by logging in with a secure ID.

\section{REFERENCES}

1 Hawasli A, Lloyd L, Cacucci B. Management of choledocholithiasis in the era of laparoscopic surgery. Am Surg 2000;66:425-30; discussion 430-421.

2 Ammori BJ, Birbas K, Davides D, et al. Routine vs “on demand" postoperative ERCP for small bile duct calculi detected at intraoperative cholangiography. Clinical evaluation and cost analysis. Surg Endosc 2000;14:1123-6.

3 Cranley B, Logan H. Exploration of the common bile duct - the relevance of the clinical picture and the importance of peroperative cholangiography. Br J Surg 1980;67:869-72. 
4 DenBesten L, Doty JE. Pathogenesis and management of choledocholithiasis. Surg Clin North Am 1981;61:893-907.

5 Varadarajulu S, Eloubeidi MA, Wilcox CM, et al. Do all patients with abnormal intraoperative cholangiogram merit endoscopic retrograde cholangiopancreatography? Surg Endosc 2006;20:801-5.

6 Ragulin-Coyne E, Witkowski ER, Chau Z, et al. Is routine intraoperative cholangiogram necessary in the twenty-first century? A national view. J Gastrointest Surg 2013;17:434-42.

7 Loperfido S, Angelini G, Benedetti G, et al. Major early complications from diagnostic and therapeutic ERCP: a prospective multicenter study. Gastrointest Endosc 1998;48:1-10.

8 Spinn MP, Wolf DS, Verma D, et al. Prediction of which patients with an abnormal intraoperative cholangiogram will have a confirmed stone at ERCP. Dig Dis Sci 2010;55:1479-84.

9 Trondsen E, Edwin B, Reiertsen O, et al. Prediction of common bile duct stones prior to cholecystectomy: a prospective validation of a discriminant analysis function. Arch Surg 1998;133:162-6.

10 Abboud PA, Malet PF, Berlin JA, et al. Predictors of common bile duct stones prior to cholecystectomy: a meta-analysis. Gastrointest Endosc 1996;44:450-5.

11 Hauer-Jensen M, Karesen R, Nygaard K, et al. Predictive ability of choledocholithiasis indicators. A prospective evaluation. Ann Surg 1985;202:64-8.

12 Koo KP, Traverso LW. Do preoperative indicators predict the presence of common bile duct stones during laparoscopic cholecystectomy? Am J Surg 1996;171:495-9.
13 Prat F, Meduri B, Ducot B, et al. Prediction of common bile duct stones by noninvasive tests. Ann Surg 1999;229:362-8.

14 Moffatt DC, Yu BN, Yie W, et al. Trends in utilization of diagnostic and therapeutic ERCP and cholecystectomy over the past 25 years: a population-based study. Gastrointest Endosc 2014;79:615-22.

15 Ryberg AA, Fitzgibbons RJ Jr, Tseng A, et al. Abnormal cholangiograms during laparoscopic cholecystectomy. Is treatment always necessary? Surg Endosc 1997;11:456-9.

16 Ford JA, Soop M, Du J, et al. Systematic review of intraoperative cholangiography in cholecystectomy. Br J Surg 2012;99:160-7.

17 Frossard JL, Hadengue A, Amouyal G, et al. Choledocholithiasis: a prospective study of spontaneous common bile duct stone migration. Gastrointest Endosc 2000;51:175-9.

18 Fletcher DR, Hobbs MS, Tan P, et al. Complications of cholecystectomy: risks of the laparoscopic approach and protective effects of operative cholangiography: a population-based study. Ann Surg 1999;229:449-57.

19 Fulcher AS, Turner MA, Capps GW, et al. Half-Fourier RARE MR cholangiopancreatography: experience in 300 subjects. Radiology 1998;207:21-32.

20 Palazzo L, Girollet PP, Salmeron M, et al. Value of endoscopic ultrasonography in the diagnosis of common bile duct stones: comparison with surgical exploration and ERCP. Gastrointest Endosc 1995;42:225-31.

21 Sugiyama M, Atomi Y. Endoscopic ultrasonography for diagnosing choledocholithiasis: a prospective comparative study with ultrasonography and computed tomography. Gastrointest Endosc 1997;45:143-6. 